Research Paper

\title{
Endophytic fungi producing of esterases: Evaluation in vitro of the enzymatic activity using $\mathrm{pH}$ indicator
}

\author{
Helen Cristina Fávero Lisboa ${ }^{1,2}$, Carolina Rabal Biasetto ${ }^{1}$, João Batista de Medeiros ${ }^{1}$, \\ Ângela Regina Araújo ${ }^{1}$, Dulce Helena Siqueira Silva ${ }^{1}$, Helder Lopes Teles ${ }^{2}$, \\ Henrique Celso Trevisan ${ }^{1 *}$ \\ ${ }^{1}$ Instituto de Química, Universidade Estadual Paulista “Julio de Mesquita Filho”, Araraquara, SP, Brazil. \\ ${ }^{2}$ Instituto de Ciências Exatas e Naturais, Universidade Federal de Mato Grosso, \\ Rondonópolis, MT, Brazil.
}

Submitted: September 9, 2010; Approved: November 13, 2012

\begin{abstract}
A sensitive and efficient colorimetric method was optimized for detection of esterase enzymes produced by endophytic fungi for development of High-Throughput Screening (HTS). The fungi were isolated and obtained previously from plant species of Cerrado and Atlantic Forest located in areas of environmental preservation in the State of Sao Paulo / Brazil, as part of the project "Chemical and biological prospecting endophytic fungi associated to plant species of Cerrado and Atlantic Forest". The compounds ethyl butyrate, ethyl acetate and methyl propionate were used as standards esters which were hydrolyzed by extracellular enzyme from endophytic fungi (EC. 3.1.1.1 - carboxylesterases) for production of carboxylic acids. Thus, the reduction of the $\mathrm{pH}$ increases the protonated indicator concentration (bromothymol blue), changing the color of the reaction medium (from blue to yellow), that can be observed and measured by spectrophotometry at $616 \mathrm{~nm}$. The methodology with acid-base indicator was performed on 13 microorganisms, aiming Periconia atropurpurea as a potential source of esterase for biotransformation of short chain esters. The results also evidenced that this methodology showed to be efficient, fast, cheap, having low consumption of reagents and easy development, and can be applied to screen carboxylic-ester hydrolases in a large number of microorganisms.
\end{abstract}

Key words: esterase, $\mathrm{pH}$ indicator, enzyme activity, endophytic fungi.

\section{Introduction}

The use of isolated enzymes and of competitive processes based on the enzyme-microorganisms relationship has been growing fast in the industrial field, due to more economical methods of production, new applications and new enzymes (Van Beilen and Li, 2002; Patel 2002; Pizarro and Park, 2003).

Owing to the numerous applications of these biocatalysts, the continual discovery of enzymes or improvement of the existing ones are necessary (Baratto et al., 2011). Thus, the survey of enzyme activities from different natural sources is presented with significant potential. In this context, assays are indispensable for the discovery of new enzymes and/or selection of those most effective in large libraries microorganisms (Beisson et al., 2000).

The development of extensive and persistent bioprospecting has contributed to the supply of high performance biocatalysts, increasing the use of microbial enzymes for creating new and simple routes to generate chemical reactions and production of derived in large scale (Ogawa and Shimizu, 2002; Schmid et al., 2001).

Among the enzymes of interest in catalysis are the esterases (EC. 3.1.1.1 - carboxylesterases) widely found in animals, plants and microorganisms, but with poorly defined physiological functions (Beisson et al., 2000). These

Send correspondence to H.C.F. Lisboa. Instituto de Ciências Exatas e NaturaisUniversidade Federal de Mato Grosso, Campus de Rondonópolis. Rodovia Rondonópolis, Guiratinga km 6, Bairro Sagrada Família, Rondonópolis, MT, Brazil. E-mail: helcrisiq@yahoo.com.br.

*In memoriam. 
enzymes are hydrolases (carboxylic-ester hydrolases) with important application due to its high stability, especially in organic solvents (Bornscheuer and Kazlauskas, 2006; Liese et al., 2006). Many esterases are commercially available and used in the synthesis of optically active compounds of lipids and domestic detergents (Schmidt and Bornscheuer, 2005). Another feature of these enzymes is the absence of cofactors and high regio-and stereospecificity, making them important tools (Gupta et al., 2003). Esterases catalyze the breaking and formation of ester ligands, where its action is usually restricted to short-chain fatty acids soluble in water (Trevisan et al., 2006).

The simplest methods for the exploration of biocatalysts, such as the esterases, are based on the monitoring of reactions of interest through colorimetric or fluorimetry measures. These methods can also be applied based on the concept of High-Throughput Screening - HTS, which shows high reproducibility, reliability and quick response, differentiating them from other traditional methods such as HPLC, GC, LC-MS, among others, that are not developed for HTS (Wahler and Reymond, 2001).

Amongst the different spectrophotometric methods, the $\mathrm{pH}$ indicator method has the advantage of simplicity and low cost. In this screening method the formation of the product of a particular enzymatic reaction is monitored by adding a $\mathrm{pH}$ indicator to the medium of reaction, in which the color change of the medium is proportional to enzyme activity. The principle of the method is assured when the buffer and the indicator present equal or near values of pKas, demonstrating equivalence of proton affinity, in an optimum $\mathrm{pH}$ for enzymatic activity (Banerjee et al., 2003).

In this study the bromothymol blue $\mathrm{pH}$ indicator was used, which has a turning range that is adequate for monitoring the change in $\mathrm{pH}$ due to acid formation from substrates esters. For the development of this method, there was an evaluation of esterase activity in 13 endophytic fungi isolated from nine plant species, and three substrates were used: ethyl butyrate, ethyl acetate and methyl propionate, which after hydrolysis by esterases produced butyric acid, acetic acid and propionic acid, respectively.

\section{Materials and Methods}

\section{Instrumentation, equipment and reagents}

The tests were performed in polypropylene microplate with 96 flat bottom holes $(300 \mu \mathrm{L})$, and the absorbance determined in a microplate reader from Biotek, Synergy HT Multi-Mode. Reagents used were ethyl butyrate $99.0 \%$ of Acros-Organics, ethyl acetate $99.5 \%$, methyl propionate $99.5 \%$ and acetone $99.5 \%$ of Sigma-Aldrich, anhydrous monobasic sodium phosphate and dibasic anhydrous $99.0 \%$ of Vetec. Controls butyric acid $99.5 \%$ and acetic acid $99.8 \%$ were obtained from Neon, and propionic acid $99.0 \%$ of Mallinckrodt. The bromothymol blue indicator was purchased from Synth and the PDA (Potato Dex- trose Agar) and PDB (Potato Dextrose Broth) culture media from Acumed.

\section{Microorganisms}

The fungi were isolated from plant species of Cerrado and Atlantic Forest located in areas of environmental preservation in the State of Sao Paulo, Brazil (Joly et al., 2010). The plant species are listed (Table 1), and fungi isolated are described in codes.

\section{Maintenance and reactivation of strains}

The fungi used were originally preserved in water by Castellani method (Rodrigues et al., 1992) at $4{ }^{\circ} \mathrm{C}$ and were reactivated by $72-96 \mathrm{~h}$ at $28{ }^{\circ} \mathrm{C}$ in test tubes or Petri dish containing PDA medium, prepared with $39.0 \mathrm{~g}$ of medium/ $1 \mathrm{~L} \mathrm{H}_{2} \mathrm{O}$.

\section{Fermentation conditions and preparation of fungi for biocatalyst screening tests}

After reactivation, the fungi were grown separately in $20 \mathrm{~mL}$ of PDB medium prepared with $24 \mathrm{~g}$ of medium / $1 \mathrm{~L} \mathrm{H}_{2} \mathrm{O}$ at $28{ }^{\circ} \mathrm{C}$ under orbital agitation $(100 \mathrm{rpm})$ for $72 \mathrm{~h}$. Small amounts of the grown colonies were removed, filtered, washed with sterile water and transferred to a $1.5 \mathrm{~mL}$ eppendorf tube, where they were weighed. Cells were re-suspended in phosphate buffer $(0.2 \mathrm{mM}, \mathrm{pH} 7.8$, pKa 7.2) in sufficient quantity to achieve concentrations of $1 \mathrm{~g} / \mathrm{L}$.

\section{Colorimetric method using $\mathrm{pH}$ indicator}

The formation of carboxylic acid due to hydrolysis of substrates mediated by esterase causes a reduction in the $\mathrm{pH}$, which change the color of the medium (blue to yellow). This reaction can be observed or monitored spectrophotometrically at $616 \mathrm{~nm}$ (Figure 1).

Table 1 - Host plants species and endophytic fungi associated.

\begin{tabular}{llc}
\hline Plant species & Endophytic fungi isolated & $\begin{array}{c}\text { Identification } \\
\text { codes }\end{array}$ \\
\hline Arrabidaea samydoides & Xylaria sp. & AS-03 \\
Casearia sylvestris & Xylaria sp. & CSY-03 \\
Cassia spectabilis & Phomopsis cassiae & CL-06 \\
& Acremonium sp. & CL-02 \\
Cupania vernalis & Phoma herbarum & CV-01 \\
& Coniothyrium minitans & CV-03 \\
& Ustilaginoidea sp. & CV-04 \\
Ocotea corymbosa & Trichoderma viridae & CV-06 \\
Rudgea viburnioides & Chaetonium sp. & PAJ-01 \\
Styrax camporum & Phomopsis stipata & SC-03 \\
Styrax ferrugineus & Paecilomyces sp. & SF-021 \\
Xylopia aromatica & Periconia atropurpurea & XIA-04 \\
\hline
\end{tabular}



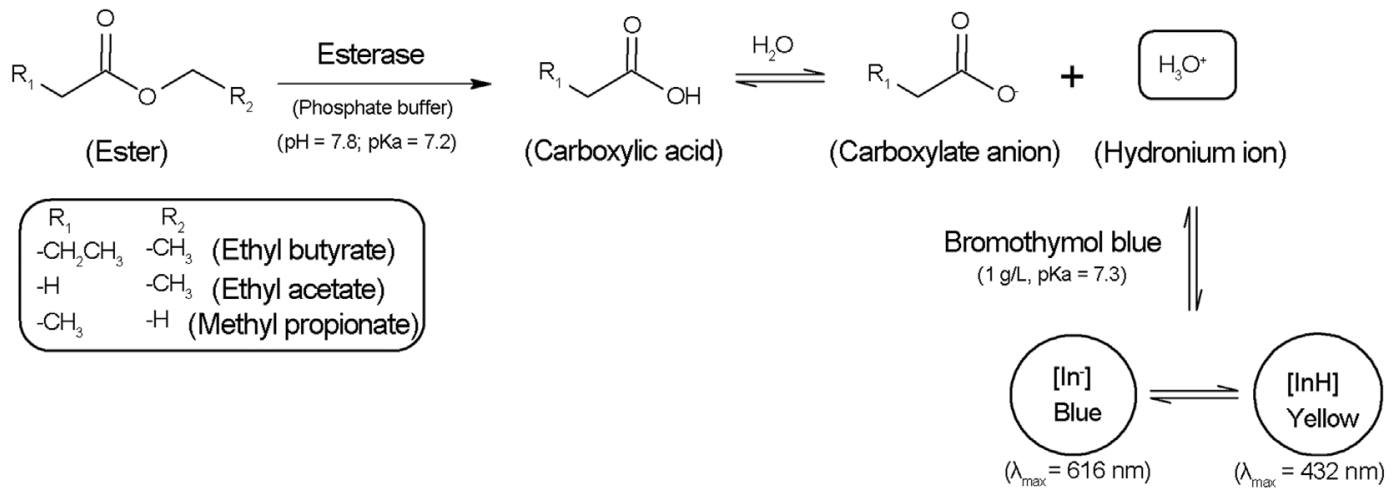

Figure 1 - Colorimetric method for esterase determination using $\mathrm{pH}$ indicator.

The substrates ethyl butyrate, ethyl acetate and methyl propionate were prepared in acetone at a concentration of $2 \mu \mathrm{L} / \mathrm{mL}$, and the bromothymol blue indicator (which range is in turn $\mathrm{pH} 6.0$ to 7.6 , with $\mathrm{pKa} 7.3$ ) as a aqueous solution buffered at a concentration of $1 \mathrm{~g} / \mathrm{L}$.

In this assay, $80 \mu \mathrm{L}$ of each test solution (fungal suspension at $1 \mathrm{~g} / \mathrm{L}$ ) was placed in $100 \mu \mathrm{L}$ of phosphate buffer, $20 \mu \mathrm{L}$ of each substrate separately and $6 \mu \mathrm{L}$ of $\mathrm{pH}$ indicator in triplicate. After 10 hours incubation at room temperature of $28^{\circ} \mathrm{C}$, the color variation of the reaction medium was determined spectrophotometrically. The carboxylic acids formed as reaction products (butyric acid, acetic acid and propionic acid) were prepared at a concentration of $2 \mu \mathrm{L} / \mathrm{mL}$ and used as positive control and buffer solution as negative control.

\section{Results and Discussion}

The test for detecting enzymatic activity using this indicator is known and suitable for the enzyme nitrilase (Banerjee et al., 2003). Thus, it was performed the adequacy and standardization of the methodology for application in screening of esterase activity in endophytic fungi, seeking employment in HTS.

The action of esterase in the reaction medium leads to ester hydrolysis of the substrate, forming the carboxylic acid. The acid undergoes ionization in aqueous solution increasing the hydronium ion concentration, favored by high $\mathrm{pH}$ (7.8), and directly influences chemical equilibrium between ionized and nonionized of bromothymol blue (Figure 1). Thus, the increasing in esterase enzyme activity leads to decreasing of $\mathrm{pH}$ and consequent reduction of concentration of protonated form of blue bromothymol and absorbance of the sample to $616 \mathrm{~nm}$.

It was also considered that the esterases have a broad range of activity for hydrolysis ( $\mathrm{pH} 6.0 \sim 8.5$ ) and its optimum can vary depending on its structure (Trevisan et al., 2006). Therefore, the $\mathrm{pH}$ of assay was standardized in 7.8, suitable to the use of bromothymol blue.

The method with acid-base indicator was used for screening of esterase in 13 endophytic fungi previously iso- lated, and the presence of extracellular fungal enzyme could be confirmed against three esters substrates.

Table 2 shows the levels of enzymatic activity determined by this methodology, being proportional to the absorbance bands of the positive $(\mathrm{A}=0.050)$ and negative $(\mathrm{A}=0.864)$ controls.

It may be noted that the fungus Periconia atropurpurea (XIA-04) showed high activity esterase for the smaller chain esters, ethyl acetate and methyl propionate and an intermediary activity for ethyl butyrate. The absorbance values detected for ethyl acetate $(\mathrm{A}=0.200)$ and methyl propionate $(\mathrm{A}=0.106)$ were highlighted in comparison to other fungi evaluated, aiming $P$. atropurpurea as a potent source of esterase for biotransformation of short chain esters.

Table 2 - Levels of esterase activity presented by endophytic fungi using different substrates.

\begin{tabular}{lccc}
\hline Fungi & \multicolumn{3}{c}{ Substrates } \\
\cline { 2 - 4 } & Ethyl butyrate & Ethyl acetate & Methyl propionate \\
\hline AS-03 & + & ++ & + \\
CSY-03 & ++ & ++ & ++ \\
CL-02 & ++ & + & + \\
CL-06 & ++ & ++ & ++ \\
CV-01 & ++ & ++ & ++ \\
CV-03 & + & + & + \\
CV-04 & ++ & ++ & ++ \\
CV-06 & + & + & + \\
PAJ-01 & + & + & + \\
RUV-04 & + & + & + \\
SC-03 & + & + & + \\
SF-021 & ++ & ++ & ++ \\
XIA-04 & ++ & ++ & +++ \\
\hline
\end{tabular}

$(+++)$ High activity $\left(\mathrm{A}^{*} \leq 0.215\right) ;(++)$ Intermediary activity $\left(0.216 \leq \mathrm{A}^{*}\right.$ $\leq 0.480)$; $(+)$ Low activity $\left(0.481 \leq \mathrm{A}^{*} \leq 0.745\right)$; Activity no detected $\left(\mathrm{A}^{*} \geq 0.745\right)$.

*Absorbance. 
The presence of the carboxylic-O-methyl group in methyl propionate is evidently favored for the reaction with $P$. atropurpurea, since it resulted in doubling enzymatic efficiency in comparison with carboxylic-O-ethyl of ethyl acetate, detected by absorbance readings. It can also be suggested that the primary chain extension of the ester leads to attenuation of esterase activity in this fungus, since the absorbance reading for ethyl butyrate $(\mathrm{A}=0.401)$ expressed a considerable reduction in hydrolysis.

The other fungi also revealed the presence of esterase, but expressing catalytic activity in low and intermediate levels of intensity. Absorbance readings showed no significant variations between the esters substrates evaluated, suggesting the absence of selectivity for different sizes of carbonic chains.

Results show that the optimization of efficient methodologies which are able to screen enzymes in a large number of microorganisms simultaneously, in reduced time, takes place as a viable option. They also highlight the endophytic fungi potential associated with plant species of Cerrado and Atlantic Forest as successful producers of esterases. Such evidence suggests that endophytes of this biome can also produce various enzymes by the competitive environment in which live.

In conclusion, the method for detecting esterase-producing microorganisms by means of the bromothymol blue indicator showed to be efficient, fast, cheap, having low consumption and easy development, which may be suitable for preliminary screening of these enzymes by HighThroughput Screening (HTS). This methodology led to discovery of the endophytic fungus Periconea atropurpurea as a potential source of esterase. Other 32 no yet identified endophytic fungi from Cerrado and Atlantic Forest were also evaluated with this technique, presenting expressive and supporting results.

\section{Acknowledgments}

The authors are grateful to the São Paulo State Research Foundation (FAPESP) within the "BioprospectaFAPESP" - The São Paulo State Bioprospecting Network (www.bioprospecta.org.br) for financial support. H.C.F. Lisboa and C.R. Biasetto also acknowledge the CAPES (Coordenação de Aperfeiçoamento de Pessoal de Nível Superior) and $\mathrm{CNPq}$ (Conselho Nacional de Desenvolvimento Científico e Tecnológico) for fellowships respectively.

\section{References}

Banerjee A, Kaul P, Sharma R, Banerjee UC (2003) A highthroughput amenable colorimetric assay for enantioselective screening of nitrilase-producing microorganisms using $\mathrm{pH}$ sensitive indicators. J Biomol Screen 8:559-565.

Baratto CM, Salamoni SP, Cost R, Oliveira CB, Locatelli GO (2011) Selection of microorganisms hydrolytic enzymes producer isolated from the midwest region of Santa Catarina, Brazil. Evidência 11:15-28.

Beisson F, Tiss A, Riviere C, Verger R (2000) Methods for lipase detection and assay: a critical review. Eur J Lipid Sci Technol 2:133-153.

Bornscheuer UT, Kazlauskas RJ (2006) Hydrolases in organic synthesis regio- and stereoseletive biotransformations. Wiley-VCH, Weinheim.

Gupta R, Rathi P, Gupta N, Bradoo S (2003) Lipase assays for conventional and molecular screening: An overview. Biotechnol Appl Biochem 37:63-71.

Joly CA, Ricardo RR, Metzger JP, Haddad CFB, Verdade LV, Oliveira MC, Bolzani VS (2010) Biodiversity conservation research, training, and policy in São Paulo. Science 328:1328-1320.

Liese A, Seelbach K, Wandrey C (2006) Industrial Biotransformations: a collection of process. Wiley-VCH, Weinheim.

Ogawa J, Shimizu S (2002) Industrial microbial enzymes: their discovery by screening and use in large-scale production of useful chemicals in Japan. Curr Opin Biotechnol 13:367375.

Patel RN (2002) Microbial/enzymatic synthesis of chiral intermediates for pharmaceuticals. Enzyme Microb Technol 31:804-826.

Pizarro AVL, Park EY (2003) Lipase-catalyzed production of biodiesel fuel from vegetable oils contained in waste activated bleaching earth. Process Biochem 38:1077-1082.

Rodrigues EG, Lirio VS, Lacaz CS (1992) Preservação de fungos e actinomicetos de interesse médico em água destilada. Rev Inst Med Trop 34:159-165.

Schmidt M, Bornscheuer UT (2005) High-throughput assays for lipases and esterases. Biomol Eng 22:51-56.

Schmid A, Dordick JS, Hauer B, Kiener A, Wubbolts M, Witholt B (2001) Review article Industrial biocatalysis today and tomorrow. Nature 409:258-268.

Trevisan HC, Medeiros JM, Lisboa HCF (2006) Extração de esterase de fígado de porco. Quim Nova 29:865-867.

Van Beilen JB, Li Z (2002) Enzyme technology: an overview. Curr Opin Biotechnol 13:338-344.

Wahler D, Reymond JL (2001) High-throughput screening for biocatalysts. Curr Opin Biotechnol 12:535-544.

All the content of the journal, except where otherwise noted, is licensed under a Creative Commons License CC BY-NC. 